\title{
Context Analysis of User Decision based on Social Learning
}

\author{
http://dx.doi.org/10.3991/ijet.v8i4.2939 \\ B.Z. Lee ${ }^{1}$, H.Y. Lu ${ }^{1}$, S.H. Ma ${ }^{1}$, X.P. Song ${ }^{2}$ \\ ${ }^{1}$ Jiangsu University of Science and Technology, Zhenjiang 212003, China \\ 2 Jiangsu University, Zhenjiang 212013, China
}

\begin{abstract}
We analyzed the context mechanism of users' decision behaviors in social tagging, and revealed the nature of social learning among users in social contexts. To improve the results of social tagging, we can select corresponding contexts according to users' given knowledge backgrounds and preferences. On the other hand, we can also recognize users' knowledge backgrounds and preferences according to their annotation results in relevant contexts.
\end{abstract}

Index Terms-Context analysis, Social learning, Social tagging, User decision

\section{INTRODUCTION}

User-generated content (UGC) is a core feature of second-generation World-Wide Web applications subsumed under the label "Web 2.0" [7][16]. In the Web 2.0 environment, users can initiatively create and organize relevant Web content [1]. In this process, users' decision behaviors may be influenced by kinds of factors, including their own knowledge backgrounds and the contexts around them. To improve users' decision behaviors and their selected results, the relations between users' decision behaviors and their knowledge backgrounds in given contexts should be revealed in certain Web 2.0 environment.

Web 2.0 tools and technologies, such as Blogs, Wikis, RSS, P2P, Social tagging, and so on, offer rich opportunities to move away from the highly-centralized industrial model of learning in the past decade, towards achieving individual empowerment of users through designs that focus on collaborative, networked communication and interaction [18].

As one of the most convenient and efficient Web2.0 tools, social tagging service provides users the ability to record web pages, and annotate those records with significant words that describe the pages being recorded [5][23], namely, social tagging is the technology and platform, through which information users can select significant words as tags according to their preferences and cognition to annotate the properties of related information resources, and form associated relation among users by related tagging actions. Examples include Delicious (www.delicious.com), CiteULike (www.citeulike.org), and so on.

Social tagging behavior is a more personalized, communicative form of the World Wide Web that emphasizes active participation, connectivity, collaboration and sharing of knowledge and ideas among users. Some research have mainly focused on its personalized service applications, such as personalized recommendation [20], while other research have mainly focused on its social sharing applications, such as collaborative tagging [6]. Social learning among users occurs in a socio-cultural system in which users use various tools and multiple forms of interaction to create collective activities. Based on the related social learning, users can refer the actions of associated partners to select appropriate words to annotate related information resources. We have qualitatively analyzed the relations between personalization and sociality about social tagging in related research [12]. While the empirical researches about the relations between personalization and sociality about social tagging have not been comprehensively discussed in the related researches, especially about its influence on the users' decision behaviors when they select relevant tags for given information resources according to their recognitions and preferences in relevant contexts

The main problem this paper wants to discuss is the contextual influence and its results about users' decision behaviors in relevant contexts, such as users' knowledge backgrounds, social or nominal contexts around users, and so on. The contributions of this paper mainly embody in the empirical analysis of context mechanisms and social learning backgrounds about user decision in social tagging.

The remainder of the paper is structured as follows. The next section reviews the literature on requirements and notifies the operational variables about relevant concepts. We describe the research methodology of context analysis in this paper, after which the experiment results and relevant discussions are provided. The last section concludes the finding and gives an outlook for future work in this area.

\section{THEORETICAL BACKGROUND AND VARIABLES NOTIFICATION}

\section{A. Theoretical Background}

The key characteristic of decision making is the choice or selecting behavior based on given scheme. Decision making can be regarded as the mental processes (cognitive process) resulting in the selection of a course of action among several alternative scenarios. Every decision making process produces a final choice. The output can be an action or an opinion of choice [15]. From a psychological perspective, it is necessary to examine individual decisions in the context of a set of needs, 
preferences an individual has and values they seek. From a cognitive perspective, the decision making process must be regarded as a continuous process integrated in the interaction with the environment [10].

The notion of context has been extensively discussed in the literature [3][9]. Context is any information that can be used to characterize the situation of an entity [4][17]. An entity is a person, place, or object that is considered relevant to the interaction between the user and application, including the user and related application [3]. The social environment of an individual, also called social context or milieu, is the culture that she or he was educated and lives in, and the people and institutions with whom the person interacts [2]. The interaction may be in person or through communication media, even anonymous or one-way, and may not imply equality of social status. Therefore the social environment is a broader concept than that of social class or social circle. Nevertheless, persons with the same social environment often develop a sense of solidarity; they often tend to trust and help one another, and to congregate in social groups. They will often think in similar styles and patterns even when their conclusions differ.

In social tagging, context mechanism would be a major step forward for a number of information-related uses. The context will also be critical in providing social machines with the ability to manage simultaneous, but conflicting, views of data. Pervasiveness, contextawareness and adaptivity are bound to each other, that is, one implies the other one [22]. It is the capability for different users to interpret the same data in different ways that provides for the argumentation and testing so crucial to scientific discourse. The context mechanisms in the future Web, such as Web 2.0, should allow different communities to simultaneously have their own interpretations of data resources, and also to understand the interpretations of others [8].

Context analysis is a method to analyze the environment in which a business operates. Environmental scanning mainly focuses on the macro environment of a business. But context analysis considers the entire environment of a business, its internal and external environment [24]. Context analysis also refers to a method of sociological analysis associated with Scheflen [19] which believes that a given act, be it a glance at another person, a shift in posture, or a remark about the weather, has no intrinsic meaning. Such acts can only be understood when taken in relation to one another [11].

Users' decision behaviors in social tagging can be conceptualized as being influenced by three factors: (1) a person's prior personal dispositions, which include recognition and preference; (2) the impingement of social environments on that person; and (3) the interactions imply a multilevel analysis of at least two levels, that of the individual (referred to as level-1) and that of the environment (referred to as level-2). A contextual study exemplifies a multilevel analysis because it includes variables on the individual and on the environment. Contextual effects are the cross-level interactions between the personal and environmental variables, and the study of these interactions defines contextual analysis. The latter includes comparative analysis, which links the level-2 variable directly to a level-1 response [21].

\section{B. Variables Notification}

When user choices relevant words as tags to annotate related information resources in social tagging, the influence factors of user decision mainly include his recognitions and preferences as well as the contexts around him. To reveal the influence mechanisms of these factors, we try to analyze the context effects about user decision based on context analysis theories.

We try to represent these abstract concepts by related operational variables as follow:

(1) Users' knowledge backgrounds can be represented by the operational variables expertise user and nonexpertise user.

(2) The context factors around them can be presented by the operational variables social group and nominal group.

(3) The consistency of decision results in social tagging can be represented by the operational variables popular tag and unpopular tag.

\section{RESEARCH METHODOLOGY}

\section{A. Experiment Platform}

A tag is simply a word which user can use to describe a bookmark. Unlike folders, user make up tags when he need them and he can use as many as he like. The result is a better way to organize user's bookmarks and a great way to discover interesting things on the Web. A tag cloud is a list of tags where size reflects popularity. There are global tag clouds where the frequencies are aggregated over all items and users. To this kind of tag cloud, more commonly used type and size represents the number of items to which a tag has been applied as a presentation of each tag's popularity [13]. The more popular of one tag, the more consistency when it is used to annotate relevant information resources by different users. The tag cloud in typical social tagging website Delicious (www.delicious.com) is shown in Figure 1.

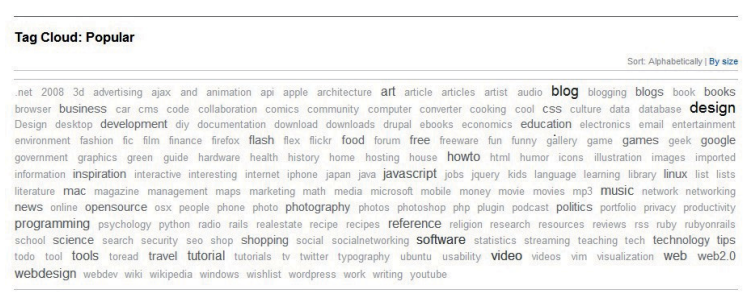

Figure 1. The popular tags in tag cloud of Delicious website

\section{B. Participants}

We selected a pool of 60 students (different from those present in Delicious website) and we asked them to take part to our experiments. Selected students showed the following features:

(1) Expertise user: 30 students were graduate students who had already taken a course in database and information systems and can be considered as expertise users. They were familiar with relevant topics of information resources in Delicious website, such as conceptual data modeling, relational model and SQL.

(2) Non-expertise user: Other 30 students were undergraduate students who had to take related 
introductory courses in databases and information systems and can be considered as non-expertise users. They had less knowledge about relevant topics of information resources in Delicious website.

\section{Experiment Design}

The 30 graduate students were randomly divided into 2 groups: the social group and the nominal group (with 15 graduate students in each group). Similarly there are 30 undergraduate students have similar division. The social group was designed to examine the social nature of the tagging process.

(1) Social group: in the social group, the tags created by a user are visible to the future users of the system. In other words, the tags created by the first participant in session 1 would be visible to every other participant in session 1 and future sessions.

(2) Nominal group: in the nominal group, the tags created by a participant are not visible to other participants in the same session or any other ensuing sessions. In other words, a participant added tags to a resource based on their own understanding about the resource. Thus, in the nominal condition, the participants worked as though they were tagging individually.

This condition was designed to work as a control group to compare with the social group described earlier. The main difference between the two conditions was the visibility of tags created by users in the earlier sessions for the users of future sessions.

Based on these regulations above, each participator can select relevant tags for interesting information resources according his knowledge background. They can select more than one times in given time, while each participator must determine one tag as the annotated results which can more represent his recognition and preference in relevant context.

\section{Results AND Discussion}

\section{A. Experiment Results}

There are four groups in this experiment, and each group has 15 participators. After the procedure of selecting tags by these participators, each person have given one tag which can more represent his recognition and preference, and there are 15 tags in each group. Among these given tags in each group, the popular tags and its frequency selected by relevant participators in related context are shown in Table 1.

TABLE I.

THE POPULAR TAGS SELECTED BY PARTICIPATORS IN CERTAIN CONTEXT

\begin{tabular}{|c|c|c|}
\hline & social group & nominal group \\
\hline $\begin{array}{l}\text { expertise } \\
\text { user }\end{array}$ & $\begin{array}{l}\text { mobile(1), linux(1), } \\
\text { business (2), } \\
\text { religion(1), education } \\
(2), \operatorname{architecture}(2)\end{array}$ & $\begin{array}{l}\text { design (2), javascript(1), } \\
\text { development(1), } \\
\text { programming }(1), \\
\text { technology(1), flash(1) }\end{array}$ \\
\hline $\begin{array}{l}\text { non- } \\
\text { expertise } \\
\text { user }\end{array}$ & $\begin{array}{l}\text { news(2), music(3), } \\
\operatorname{video}(2), \operatorname{travel}(3), \\
\text { food(1) }\end{array}$ & $\operatorname{art}(1)$, humor(1) \\
\hline
\end{tabular}

\section{B. Discussion}

According to the results above, we can get the frequencies of expertise users and non-expertise users who have selected relevant tags in different contexts. The results are shown in Table 2.

TABLE II.

FREQUENCIES OF EXPERTISE AND NON-EXPERTISE PARTICIPANTS SELECTING RELEVANT TAGS IN DIFFERENT CONTEXTS

\begin{tabular}{|c|c|c|c|c|}
\hline Context & \multicolumn{2}{|c|}{ social group } & \multicolumn{2}{c|}{ nominal group } \\
\hline $\begin{array}{c}\text { individual } \\
\text { user }\end{array}$ & $\begin{array}{c}\text { expertise } \\
\text { user }\end{array}$ & $\begin{array}{c}\text { non- } \\
\text { expertise } \\
\text { user }\end{array}$ & $\begin{array}{c}\text { expertise } \\
\text { user }\end{array}$ & $\begin{array}{c}\text { non- } \\
\text { expertise } \\
\text { user }\end{array}$ \\
\hline poplar tag & 9 & 11 & 7 & 2 \\
\hline $\begin{array}{c}\text { unpopular } \\
\text { tag }\end{array}$ & 6 & 4 & 8 & 13 \\
\hline Total & 15 & 15 & 15 & 15 \\
\hline
\end{tabular}

The value of in Table 2 is 11.9466 , and the relevant p-value is 0.0076 , more less than 0.01 , so based on the significance level of 0.01 , we can reject the null hypothesis of mutual independence between row variables (popular tag or unpopular tag) and column variables (expertise user in social group, non-expertise user in social group, expertise user in nominal group, or non-expertise user in nominal group), that is to say, there are remarkable correlation between these row variables and column variables.

Putting aside other differences in individual characteristics, for expertise and non-expertise users, these data report the number of users selecting popular tags in two contexts: users in social group (30 students) and users in nominal group (another 30 students). The two individual characteristics are a user's knowledge backgrounds and his or her selected results; the context characteristic is the conditions of selecting behaviors.

Research finding suggest that expertise users often outperform non-expertise users in selecting popular tags. This is a level-1 relationship because both variables knowledge background and selected results - are characteristics of users. The hypothetical data in the rightmost marginal Table 3 echoes this relationship: for the 60 users, $53.33 \%$ of the expertise users selected the popular tags compared with $43.33 \%$ of the non-expertise users; the difference of 10 percentage points indicates a gap in selecting popular tags.

TABLE III.

RESULTS OF TWO KINDS OF INDIVIDUAL USER IN TWO KINDS OF CONTEXTS

\begin{tabular}{|c|c|c|c|c|}
\hline context & Individual user & $\begin{array}{c}\text { Poplar } \\
\text { tag }\end{array}$ & $\begin{array}{c}\text { Unpopular } \\
\text { tag }\end{array}$ & total \\
\hline \multirow{3}{*}{$\begin{array}{l}\text { Social } \\
\text { group }\end{array}$} & Expertise user & 9 & 6 & 15 \\
\hline & $\begin{array}{c}\text { Non-expertise } \\
\text { user }\end{array}$ & 11 & 4 & 15 \\
\hline & total & 20 & 10 & 30 \\
\hline \multirow{3}{*}{$\begin{array}{l}\text { Nominal } \\
\text { group }\end{array}$} & Expertise user & 7 & 8 & 15 \\
\hline & $\begin{array}{c}\text { Non-expertise } \\
\text { user }\end{array}$ & 2 & 13 & 15 \\
\hline & total & 9 & 21 & 30 \\
\hline \multirow{3}{*}{$\begin{array}{c}\text { Marginal } \\
\text { table }\end{array}$} & Expertise user & 16 & 14 & 30 \\
\hline & $\begin{array}{c}\text { Non-expertise } \\
\text { user }\end{array}$ & 13 & 17 & 30 \\
\hline & total & 29 & 31 & 60 \\
\hline
\end{tabular}

The comparative analysis directly links the users' selected results (level-1) to the condition of selecting behavior (level-2): collapsing the distinction between 
expertise users and non-expertise users (i.e.. marginalizing over knowledge background), the first two total columns show that $66.67 \%$ of the users in social group selected the popular tags compared with $30 \%$ of the users in nominal group. Apparently, the condition of selecting behavior has a positive effect of 36.67 percentage points.

The contextual analysis examines how the condition of selecting behavior (level-2) influences the relationship between the two individual characteristics (level-1). The left-most partial table shows that when in the social group, expertise users are less likely to select the popular tags than non-expertise users, $60 \%$ compared with $73.33 \%$, a difference of 13.33 percentage points. However, the right-most partial table shows that when in normal group, expertise users are more likely to select popular tags than non-expertise users, $46.67 \%$ compared with $13.33 \%$, a difference of 33.34 percentage points.

TABLE IV.

THE PERCENTAGE OF EXPERTISE AND NON-EXPERTISE USERS SELECTING POPULAR TAGS IN DIFFERENT CONTEXTS

\begin{tabular}{|c|c|c|c|}
\hline & $\begin{array}{c}\text { social } \\
\text { group(\%) }\end{array}$ & $\begin{array}{c}\text { nominal } \\
\text { group(\%) }\end{array}$ & $\begin{array}{c}\text { difference in } \\
\text { popular (\%) }\end{array}$ \\
\hline expertise user & 60 & 46.67 & 13.33 \\
\hline $\begin{array}{c}\text { non-expertise } \\
\text { user }\end{array}$ & 73.33 & 13.33 & 60 \\
\hline $\begin{array}{c}\text { non-expertise } \\
\text { user gap }\end{array}$ & 13.33 & -33.34 & 46.67 \\
\hline
\end{tabular}

Holding constant the individual-level effects of knowledge background and the comparative effects of the conditions of selecting behavior, shown in Table 4, the contextual effect (synonymously, cross-level interaction effect) suggests that non-expertise users in social group will more likely select the popular tags (60 percentage points) than expertise users in social group $(46.66 \%$ percentage points); an average cross-level interaction effect is $23.33 \%$ (difference in gain divided by 2 ).

Users' decision behaviors and related results in social tagging not only dependent on their relevant knowledge backgrounds, but also dependent on the contexts around them. Based on the results and context analysis above, we try to reveal the causes which may influence users' decision behaviors in certain knowledge backgrounds and given contexts.

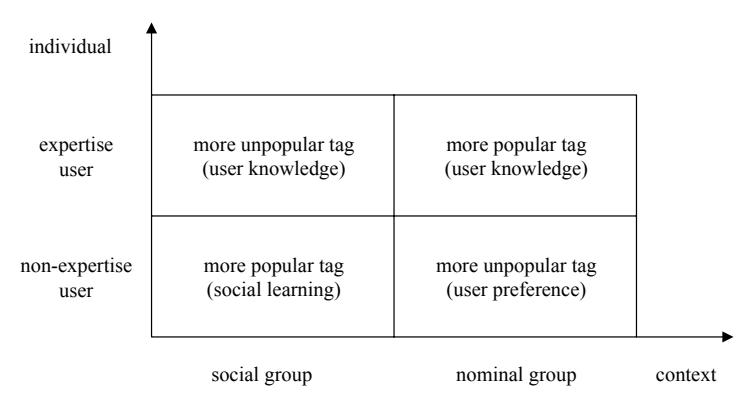

Figure 2. The features of tags selected by relevant participants in given contexts

In the social group, non-expertise users have selected more popular tags than expertise users, for that there may be social learning behaviors among these non-expertise users. At the same time, expertise users have selected more unpopular tags than non-expertise users, for that they mainly annotate relevant information resources according to their knowledge rather than simply imitate from each other.

In the nominal group, expertise users have selected more popular tags than non-expertise users, for that they have more regular knowledge than non-expertise users. At the same time, non-expertise users have selected more unpopular tags than expertise users, for that they have more different preferences from each other.

\section{CONCLUSIONS AND FUTURE WORKS}

Users can initiatively select relevant words as tags to annotate interesting information resources in social tagging. These decision behaviors not only dependent on their knowledge backgrounds and preferences, but also dependent on the contexts around them. Popular tags in tag cloud embody the consistency when these tags are selected by users in social tagging.

Based on context analysis theories and typical social tagging website, we have revealed the relations between users' decision behaviors and their knowledge backgrounds in relevant contexts. In social context, users tend to select more popular tags, in addition, the user who has less relevant knowledge will select more popular tags than the user who has more relevant knowledge, for that there may be social learning and imitation among these non expertise users in social contexts. On the other hand, in nominal context, users tend to select more unpopular tags, in addition, the user who has more relevant knowledge will select more popular tags than the user who has less relevant knowledge, for that the selecting behaviors of participators mainly depend on their knowledge and preferences and lack imitations among them in nominal context, what's more, the expertise's selecting behaviors may be more consistent than the nonexpertise's selecting behaviors in nominal context.

Based on these contextual relations above, we can adjust corresponding contexts to improve the behaviors and results of social tagging. When users have more knowledge about annotated information resources, we can let they annotate it in relative nominal context; when users have less knowledge about annotated information resources, we can let they annotate it in relative social context. That is to say, to raise the consistency of annotated tags, we can provide more nominal contexts for the user who have more relevant knowledge, and provide more social contexts for the user who has less relevant knowledge. In addition, we can also reveal the knowledge backgrounds and preferences of participators. When a group of users select more popular tags in social context, they may be the more non-expertise users, and vice versa; at the same time, when a group of users select more popular tags in nominal context, they may be the more expertise users, and vice versa.

The sample dataset in this paper is the graduate as expertise user and the undergraduate as non-expertise user, and there may be other dataset, such as the participators from different domains, different demands, or different behavior habits, to be used to improve our context analysis in the future. To the future work, we also want to construct its quantitative regress model based on the relations between user decision and his knowledge 


\section{SPECIAL FOCUS PAPER \\ CONTEXT ANALYSIS OF USER DECISION BASED ON SOCIAL LEARNING}

backgrounds in relevant contexts. In addition, the longitude analysis may be considered in the future, for that the relations above may be varied over time.

\section{ACKNOWLEDGMENT}

The authors wish to thank the helpful comments and suggestions from reviewers.

\section{REFERENCES}

[1] C. Baladron, J. Aguiar, B. Carro, A. N. Sanchez-Esguevillas, M. Baldauf, "Integrating user-generated content and pervasive communications," Pervasive Computing, IEEE, Vol. 7 Issue 4, pp. 58-61, 2008. http://dx.doi.org/10.1109/MPRV.2008.76

[2] E. Barnett, M. L. Casper, "A definition of the social environment (Letter to the Editor)," American Journal of Public Health, vol. 91 Issue 3, pp.465, 2001.

[3] A. K. Dey, G. D. Abowd, "Towards a better understanding of context and context-awareness," Technical Report GITGVU-99-22, Georgia Institute of Technology, College of Computing, 1999.

[4] A. K. Dey. 2001, "Understanding and Using Context," Personal Ubiquitous Computing, Vol. 5 Issue 1, pp. 4-7, 2001. http://dx.doi.org/10.1007/s007790170019

[5] T. Franklin, M. V. Harmelen, "Web 2.0 for content for learning and teaching in higher education," [online], available at: www.citeulike.org/group/1572/article/1378679 (accessed 12 April 2011).

[6] S. A. Golder, B. A. Humberman, "Usage Patterns of Collaborative Tagging Systems," Journal of Information Science, Vol. 32 Issue 2 , pp. 198-208, 2006. http://dx.doi.org/10.1177/016555150 6062337

[7] P. Graham, "Web 2.0," Available online at http://www.paulgraham.com/web20.html [last visited April 4, 2011].

[8] J. Hendler, T. Berners-Lee, "From the Semantic Web to social machines: A research challenge for AI on the World Wide Web," Artificial Intelligence, Vol. 174, pp. 156-161, 2010 http://dx.doi.org/10.1016/j.artint.2009.11.010.

[9] R. Hull, P. Neaves, J. Bedford-Roberts, "Towards situated computing," Proceedings of 1st International Symposium on Wearable Computers, pp. 146-153, 1997.

[10] D. Kahneman, A. Tversky, Choice, Values, Frames, The Cambridge University Press, 2000.

[11] A. Kendon, Conducting Interaction: Patterns of Behavior in Focused Encounters, Cambridge: Cambridge University Press, 1990.

[12] B. Lee, S. Ge, "Personalisation and sociability of open knowledge management based on social tagging," Online Information Review, Vol. 34, Issue 4, pp.618 - 625, 2010. http://dx.doi.org/10.1108/14684521011073016

[13] S. Lohmann, J. Ziegler, L. Tetzlaff, "Comparison of Tag Cloud Layouts: Task-Related Performance and Visual Exploration," Gross T. et al. (Eds.): INTERACT, Part I, LNCS 5726, pp. 392404, 2009.

[14] J. McCarthy, "Formalizing context (expanded notes)," Technical Report: CS-TN-94-13, Stanford University, 1994.

[15] N. Naqvi, B. Shiv, A. Bechara, "The Role of Emotion in Decision Making: A Cognitive Neuroscience Perspective, " Current
Directions in Psychological Science, Vol. 15, Issue 5, pp.260-264, 2006. http://dx.doi.org/10.1111/j.1467-8721.2006.00448.x

[16] T. O'Reilly, 2005. "What Is Web 2.0? Design Patterns and Business Models for the Next Generation of Software," Available online

http://www.oreillynet.com/pub/a/oreilly/tim/news/2005/09/30/wha t-is-web-20.html [last visited April 4, 2011]

[17] H. Pirkkalainen, J. Pawlowski, 2013. "Global Social Knowledge Management: From Barriers to the Selection of Social Tools," The Electronic Journal of Knowledge Management, Vol. 11, Issue 1, pp.3-17, 2013.

[18] P. C. Rogers, S. W. Liddle, P. Chan, A. Doxey, "A Web 2.0 Learning Platform: Harnessing Collective Intelligence," Turkish Online Journal of Distance Education, Vol. 8, Issue 3, pp. 16-33. 2007.

[19] A. E. Scheflen, Comparative Psycholinguistic Analysis of Two Psychotherapeutic Interviews, Edited by Louis A. Gottschalk, M.D. New York: International Universities Press, 1963

[20] A. Shepitsen, J. Gemmell, B. Mobasher, R. Burke, "Personalized recommendation in social tagging systems using hierarchical clustering," in Proceedings of the 2008 ACM conference on Recommender systems in Lausanne, Switzerland, ACM New York, NY, USA, pp. 259-266, 2008

[21] R. B. Smith, Multilevel Modeling of Social Problems, Springer; 1st Edition, 2011. http://dx.doi.org/10.1007/978-90-481-9855-9

[22] A. Soylu, P. D. Causmaecker, P. Desmet, "Context and Adaptivity in Pervasive Computing Environments: Links with Software Engineering and Ontological Engineering," Journal of software, Vol. 4 Issue 9, pp.992-1013, 2009.

[23] X. Sun, H. Lin, . 2013. "Topical community detection from mining user tagging behavior and interest," Journal of the American Society for Information Science and Technology, Vol. 64, Issue 2, pp. 321-333, 2013. http://dx.doi.org/10.1002/asi.22740

[24] J. Ward, J. Peppard, 2002. The Strategic Framework. In Strategic Planning for information systems. England: John Wiley \& Sons, 2002 .

\section{AUTHORS}

B. Z. Lee is with the Jiangsu University of Science and Technology, Zhenjiang 212003, China (e-mail: bzli04@gmail.com).

H. Y. Lu is with the Jiangsu university of Science and Technology, Zhenjiang 212003, China (e-mail: luhaiyan_just@163.com).

S. H. Ma is with the Jiangsu University of Science and Technology, Zhenjiang 212003, China (e-mail: msh@tju.edu.cn).

X. P. Song is with the Jiangsu University, Zhenjiang 212013, China (e-mail: phd_sxp@163.com).

This work was supported in part by the Natural Science Foundation of China (No.71273121 and 71171100), National Philosophy and Social Science Foundation of China (No. 11\&ZD169 and 10CTQ18). It is an extended and modified version of a paper presented at the 2012 International conference on Applied Science and Engineering Innovation (ASEI2012), held in Beijing, China, December 2012. Manuscript received 18 February 2013. Published as submitted by the authors 08 August 2013. 